\title{
Time and Risk Entrepreneurial Characteristics of Growth: The Case of Persisted Light Industrial Prototypes
}

\section{P. E. Petrakis}

Athens National and Kapodistrian University, Department of Economics, Division of Economic Development, Athens, Greece. Email: ppetrak@econ.uoa.gr

Received October $15^{\text {th }}, 2009$; revised November $27^{\text {th }}, 2009$; accepted December $31^{\text {st }}, 2009$.

\begin{abstract}
This article is about the role of entrepreneurial perception of time and risk vis à vis structural change and growth. Entrepreneurship is a basic constituent element of social capital which in turn is a productive lubricant of the growth process. Different structural entrepreneurial prototypes with respect to time and risk have different structural change effects. Those structural changes (and any structural changes) are not neutral as far as the implications of growth rate changes are concerned. Therefore the time and risk characteristics of active entrepreneurship are reflected in the growth process either in the form of structural change and/or in the form of growth rate change.
\end{abstract}

Keywords: Time, Risk, Entrepreneurship

\section{Introduction}

This article is about the role of the entrepreneurial perception of time and risk vis à vis structural change and growth. Entrepreneurship is a basic constituent element of social capital which in turn is a productive lubricant of the growth process. Different structural entrepreneurial prototypes with respect to time and risk have different structural change effects. Those structural changes (and any structural changes) are not neutral as far as the implications of growth rate changes are concerned. Therefore the time and risk characteristics of active entrepreneurship are reflected in the growth process either in the form of structural change and/or in the form of growth rate change.

The analysis of the growth process, based on the Schumpeterian tradition of real economic structure change, with the development of endogenous models and the introduction of research [1] and knowledge [2] effects of human capital contribution to growth has found a respectable and well-spread acceptance. At the same time growth models have been found to be in line with developments in the real economy [3], increasing their acceptability.

However, the present mature stage of economic growth in developed countries and the challenge of sustainable growth patterns, together with the observed persisted light industrial prototypes in a number of peripheral countries (Balkans etc.) may reopen the discussion on the growth process with 'reasoned history on the time and space particularities of growth dynamics' [4].

The reopening of the discussion will be facilitated with the introduction of the extended concept of social capital as being broken down into human capital, entrepreneurship and networks effects [5].

The paper is developed as follows: Section 2 focuses on social capital, entrepreneurship and growth relationship; Sections 3 and 4 relates to the analytics of risk and time; Section 5 clarifies the time and risk dimensions of entrepreneurship; Section 6 analyses the effects of entrepreneurial time and risk on structural change. Finally conclusions will be drawn.

\section{Entrepreneurship, Social Capital and Growth}

The relation between growth and entrepreneurship appears to be easily accepted. However until now this has not yet been fully scientifically supported. First, this is because the phenomenon of entrepreneurship lacked a conceptual framework by itself [6]. Also for a very big period of time the significance/meaning of entrepreneurship had been excluded [7] from the picture with equilibrium approaches in economics [8].

Adam Smith [9] formed the conditions of introducing entrepreneurship as an engine of growth since he recognises that the only restriction on sustainable growth is division of labour and the extent of the market. Thus entre- 
preneurship (innovation) extends the market and increases productivity and therefore causes economic growth. Moreover if we accept that entrepreneurship opportunities already exist but were unnoticed [10] and profit, as a reward of entrepreneurship, is the engine that moves the system away from equilibrium (Schumpeter [11] and in a decentralised context, Hayek [12], then we may have a logical consequence of growth. On the other hand, Ricardo [13] set the principles of growth as they were organised in the model of Solow [14]. Only by investing in capital (K), can production $(\mathrm{Y})$ be increased and thus productivity will increase. The restrictive terms will emanate from fixed factors of production and the diminishing marginal factor productivity. Any other influences in the productive process should be searched in the Solow residual [15].

Lucas [2] rearranges the neoclassical model and introduces the idea that attention should be on the labour factor 1 and the external effects of human capital. Romer $[1,15]$ adds that additional investment in research could produce increasing returns through knowledge spillover embodied in human capital. The aspect of knowledge that is crucial is alertness [10], that is the 'knowledge' of where to find market data [16]. The entrepreneurial discovery process is associated with the actor's interpretation framework, or the stock of knowledge, which is derived from everyday life experiences [17].

The concept of social capital has been put forward alongside the traditional concept of financial, real and human capital during the 1990s [18] and it has recently been related to entrepreneurship [19]. According to Bourdien and Wacquant [20] social capital is an individual or group-related resource that accrues by possessing a durable network of more or less institutionalised relationships. According to Coleman [21,22] it is to be found in the relations between individuals and it includes obligations, expectations, information channels and social norms [5], like high-trust and low-trust attitudes (Fukuyama 1995) or family-based social trust vs communitybased trust [23]. Social capital should be regarded as the most diversified of capital forms. The extent of the diversification will largely depend on how its basic nature is analysed: Coleman's [22] endogenous phenomenon of social relations vs Fukuyama's [23] view that it is the result of society's trust and cooperation.

Woolcock [24] and Fedderke et al. [25] proposed that we should see in the concept of social capital two interacting dimensions: 'transparency' (the transaction-cost-lowering functions of social capital) and the rationalisation potential of maintaining increasing returns to scale, i.e. delaying the onset of diminishing returns. Two more notes were added to this by Piazza-Georgi: a) social capital operates to a significant extent through human skills capital and entrepreneurial skills by lowering their creation costs; b) there may be a significant substitution effect between human and social capital (towards human capital) through the increased cost of human time. If we then accept that investing in human capital is more efficient that investing in social capital we could have another reason for delaying the diminishing returns process. Thus growth and social capital are positively connected since the accumulation of the latter is fuelling the growth process.

$\mathrm{Yu}$ [17] utilising Kirzner's theory of entrepreneurial discovery, Schumpeter's two types of economic responses (extraordinary and adaptive) and the Austrian theory of institutions as building blocks, constructs an entrepreneurial theory of institutional change and social capital accumulation. Yu and others do not use the concept of social capital and institutions alternatively. However, the concept of social capital as it is defined [19] can be very closely compared with Yu's definition of institutions $[17,26]$. The process of institutional change is the continuous interaction between entrepreneurial exploitation and exploitation of opportunities [27]. Institutions (stock of knowledge) emerge as a result of human agents attempting to reduce structural (vs neoclassical static) uncertainty. Therefore, entrepreneurship enlarges institutional development and social capital accumulation. It is obvious that there are second-round effects where social capital accumulation reinforces entrepreneurship through the production of externalities which promote the distribution of information and generate asymmetric information. At the same time institutions reinforce entrepreneurial alertness and the discovery process [26]. Thus we may accept that entrepreneurship enlarges social capital accumulation. Therefore, entrepreneurship positively affects growth.

\section{Entrepreneurship and Risk}

Although as Knight proposes there is considerable difference between the concept of uncertainty and the risk (measurable) from now on we will use the two terms alternatively because there is no added value in the scope of the paper.

In our attempt to establish the positive theoretical relationship between entrepreneurship and uncertainty we may approach the subject from four different angles. The first refers to the role of social capital and the Knightian uncertainty as presented by Brouwer [28]. The second will be based on the entrepreneurial perspective of institutional change [17]. The third utilises the basic financial relationship of (entrepreneurial) return and risk [29-31] proposed by Petrakis [32]. Finally the fourth can be based on the concept of distribution of risk through the division of labour process.

According to Brouwer [28] in Knight's view, true uncertainty is the only source of profits, since profits would disappear as soon as change became predictable or it can be hedged and they will be changed into costs. Brouwer shows how the introduction of Knightian uncertainty can 
abate diminishing returns of innovative investment. This can be done by $R \& D$ cooperation, that is, by creating social capital through R\&D networks. So we can conclude that uncertainty makes perpetual innovation more likely. Thus growth and uncertainty are positively related. Knight saw rates of return on entrepreneurial investment vary around an average and it is the relative entrepreneurial ability that is rewarded.

Entrepreneurs also create a great deal of uncertainty through Schumpeterian innovation which creates confusion in the market. Lack of entrepreneurship means that we are locked up in old structures, interpretations and understandings [17]. Thus, entrepreneurial activation is positive concerned with uncertainty.

The portfolio theory, as shaped by Markowitz [29], Tobin [30] and Sharpe [31], recognised the positive relationship between expected return and risk. When an individual creates a portfolio, optimalisation is based on the risk and return relationship: risk is the result of either systematic risk or, in the case of imperfect unsystematic risk, diversification due to project indivisibility or project interrelationships [33] or a combination of both. Given these prerequisites, the risk premium that the economic agent enjoys is the entrepreneurship premium that we come across in entrepreneurship theories.

The relationship of risk and growth can be approached from a more general point of view. This can be done if we consider the growth process as facilitated by divisions of the labour process. Thus, the division of labour not only increases developments in specification and broadens labour skills expertise and therefore increases rates of returns but also by necessity distributes the risks around different economic activities. The distribution of risk, and thus the lowering of the prevailing risk levels, increases the discounted (by risk) rates of returns.

From the above analysis, irrespective of the angle we approach the issue under discussion, we can conclude that entrepreneurship and uncertainty are related with the latter positively affecting entrepreneurship. Finally, we may conclude that growth and uncertainty are related with the latter positively affecting growth.

Risk reflects the degree of uncertainty and potential loss associated with the outcomes which may follow from a given behaviour or a set of behaviours [34]. Yates and Stone [35] identify the basic element of risk construction: potential losses and the significance of those losses. The point of research focuses on how entrepreneurs cope with the risks inherent in their decisions, what determines the way they perceive the riskiness of their decisions, whether they posses character traits which predispose them to engage in uncertain behaviour or whether they assess opportunities and threats differently from nonentrepreneurs [36].

In any case entrepreneurs' risk-taking decisions are ex- tremely complex [37]. This is quite an obvious conclusion and has been stated very clearly from Knight [38] to Baird and Thomas [39] with their contingency model of strategic risk-taking.

Sitkin and Weingart [40] summarise the whole framework of risk decision in two main sub-domains: outcome history and problem framing [41] as mediated in two crucial entrepreneurial variables: entrepreneurial risk propensity and perception of risk. Problem framing refers to whether a situation is presented to decision-makers as an opportunity or a threat. Outcome history is a person situation interaction characteristic defined as the degree to which the decision-maker believes that previous riskrelated decisions have resulted in successful or unsuccessful outcomes [40]. Correspondingly risk perception is defined as an individual's assessment of how controllable that uncertainty is [39] and risk propensity is defined as an individual's current tendency to take or avoid risk.

The concept of meditation on risk perception has also been stated in the work of Hean Tat Keh et al [42]. Their model also recognises four independent variables (overconfidence, belief in the law of small numbers, planning fallacy and illusion of control) and two control variables (demographics and risk propensity). The researchers have been utilising the work of Simon et al [43] who found that the significant relationships are illusion of control belief in the law of small numbers with risk perception (negative relationship). Illusion of control and belief in the law of small number affects uncertain decisions positively and risk perception negatively. The same authors identify that flexibility, optimism and risk propensity affect a decision-maker's tolerance of risk.

Derived from the above analysis is the fact that risk perception mediates the relationship between cognitive biases and decisions under risk. Although enough theorisation has been developed about these associations [44-46] the question about how cognitive biases i.e. common types of mental stochastics used to make judgments [43] lead individuals to perceive different levels of risk in the same decision situation needs further classification. This is despite the empirical evidence on the role of overconfidence, illusion of control etc. produced by Simon et al. [43] mainly because those approaches are partial equilibrium approaches. In other words, when we study such a complex phenomenon it is very difficult to isolate the influences of even basic factors that influence the decision under risk. This point should be taken into account when we examine well- supported evidence $[47,48]$ that risk tolerance or ambiguity tolerance do not reside differently in entrepreneurs. However, there is a discussion [49] that risk and ambiguity have different and distinguished effects on entrepreneurial behaviour and specifically that the presence of ambiguity accentuates the perception of risk. 


\section{The Entrepreneurial Perception of Time}

According to Shane and Venkataraman [6] entrepreneurship also means the process by which opportunities to create future goods and services are discovered, evaluated and exploited. In the framework of a well-structured theory for tracing and developing entrepreneurial opportunities [50] two levels of analysis appear. The first includes the process of tracing and developing entrepreneurial opportunities (development, recognition, perception, discovery and evaluation) while the second includes the factors that influence this process (entrepreneurial alertness, information asymmetry and prior knowledge, discovery versus purposeful search, social networks and finally personality traits).

The individual according to his or her sensitivity alertness $[10,51]$ reacts to the information $\mathrm{s} / \mathrm{he}$ receives and recognises the entrepreneurial opportunity. At that moment the entrepreneurial opportunities are continuously evaluated either within a formal or informal process [52]. The individual informally collects information until it becomes more formal and particularly when the collaboration of third parties is necessary in the search for essential resources. If the result of this process is satisfactory, then a feasibility study is produced. The personal trait of preference of time has its role through the Stage-Gate procedure [50] or, alternatively, through the Passage via the Knowledge Corridor [53]. Thus, the process of the evaluation of time acts upon entrepreneurship as one continuous screening procedure.

Entrepreneurs develop their entrepreneurial alertness either on the grounds of backward or forward interpretation [17] of incoming information and only to the level that they pace with their time preference. For example, they exclude from their evaluation all information (in this case preference for short-term entrepreneurship) connected to long-term entrepreneurship. Thus entrepreneurial alertness is not a complete process but a unilaterally developed sensitivity which is biased in favour of shortterm actions. Note that in cases where a long-term perception of time prevails in society, then the long-term entrepreneurial trap can arise where no immediate results in entrepreneurial activity are taking place. In other words the entrepreneur's time preference is something more than a simple recognition of cost difference of the present vs the future. Thus, the time preference is a personal attitude of the entire process of opportunity tracing and development. Basically it consists of a characteristic of the social capital and a characteristic of the entrepreneurial lifestyle [19].

The final phase of the evaluation, by using time discount of future inflows, constitutes only part of the influence of the time preference on the process of entrepreneurship. Time preference is much more important in all previous stages of the process of opportunity, identifica- tion and development. Thus, for example, the businessperson with a powerful preference for the present will never be interested in assembling information and consequently in developing his or her alertness with regard to sectors which require a large degree of engagement of resources and thus a long period of depreciation. Thus accidental discovery [54] is dramatically decreased. Moreover social networks $[55,56]$ are shaped under the influence of a specific perception of preference of time, which they also transmit to the candidate entrepreneur. In this way, they contribute to the reproduction of entrepreneurial opportunities which obey specific values of time [57].

The relevant questions which are the subject of this paper refer to whether the average ideal duration of entrepreneurial commitment can be considered as the outcome of a linear or non-linear approach towards time perception; furthermore, whether it is a state of the world situation or an event (or a sequence of events); and finally whether this is an objective or a subjective perception.

In any case we can accept that how the present is determined depends on the subjective perceptions of the entrepreneur [58,59]. Moreover the concept of the average ideal duration of entrepreneurial commitment fits more with the notion of states of the world assessment of time rather than to the point of view of a single event (or a consequence) of events. The entrepreneur engages himself in a situation where its implications are diffused in a continuous time assessment and are not restricted to a single calculation or a solid conclusion.

\section{Entrepreneurship, Time and Risk}

The development of the decision-making investment process within the standard neoclassical model has shaped time into a simple, mono-dimensional factor of decisionmaking. This happened with the same simplicity that also forced out the entrepreneur's role from the function of the economic system [7].

But the question of preference of time is too important for the process of entrepreneurship and, therefore, for us to ignore. Temporal dynamics are at the heart of entrepreneurship [60]. Anything that involves an entrepreneur rial organisational process (including the decision of resources commitment) has its time-dimensional character. When the process of evaluation is conducted in terms of excessive preference for the present over the future, very few or no entrepreneurial plans are going to materialise. Additionally it is very unlikely that specialised markets of time and risk are going to help the investor to materialise his or her investment. Moreover, it is known that very few similar markets exist. Even if they exist, very few entrepreneurs have access to them.

The inclusion of time can be connected with significant aspects of the growth process. Time is introduced by the dynamic models and therefore it brings up the issues 
of equilibrating vs. non-equilibrating growth paths. Thus, disequilibrium based on growth (evolutionary theory) can emerge. It is also related to convergence issues. However, according to the scope of the present paper the issue of time is related and defined as the ideal duration of entrepreneurial commitment. This concept is directly related to the structural prototype prevailing in space and time since it can distinguish between short-term entrepreneurship and long-term or future-oriented entrepreneurship [61].

Decision risk is defined here, according to the extended Sitkin and Pablo [41] definition, as the extent to which there is uncertainty about whether potentially significant (satisfactory) and/or disappointing outcomes of decisions will be realised. Thus, risk reflects the degree of uncertainty and potential loss associated with the outcomes which may follow from a given behaviour or set of behaviours [34]. Yates and Stone [35] identify the basic element of risk construction: potential losses and the significance of those losses. The point of research focuses on how entrepreneurs cope with the risks inherent in their decisions, what determines the way they perceive the riskiness of their decisions, and whether they possess character traits which predispose them to engage in uncertain behaviour or whether they assess opportunities and threats differently from non-entrepreneurs [36].

In order to do so, we should clarify the meaning of the two basic risk concepts: risk perception and risk propensity. Thus, risk perception is a subjective concept about the controllability of uncertainty $[39,41]$. This subjective concept generally speaking is developed according to how the problems are framed (how the problem is presented to the entrepreneur, positively or negatively), the outcome history [40], the problem under consideration and the cognitive process of risk perception development. This concept could be connected with general society's sense of uncertainty controllability as a social value and it is formed at a personal level. When we speak about low (high) risk perception we are referring to a situation where the individual believes the uncertainty of outcomes is highly uncontrollable (strong controllability). Risk propensity is defined as an individual's current tendency to take or avoid risks [40,41]. It is a clear personal trait which can also be influenced by general social values (as they can influence all aspects of entrepreneurial behaviour).

Drawing and extending the work of Sitkin and Pablo [41] and Forlani and Mullins [34] we can imply that the entrepreneur's perception of risk and decisions involving risk are distinct and separate cognitive processes. Moreover the risk propensity is a separate cognitive process from risk perception. Following Sitkin and Weingart [40] and in contrast with previous researchers [62] we do not consider risk propensity as a stable personal attribute. Thus, we employ a trait-based definition which is con- structed as a cumulative tendency to take or avoid risks and can be changed as a result of experience. Risk and uncertainly is about future and therefore is about time. Thus it is generally agreed that time plays a crucial role in risk [63]. Researchers such as Vlek and Stollen [64] observed that several risk behaviours are related to time and the notion of discounting in time.

Das and Bing-Sheng Teng [61] analyse the interrelation of risk and time given that risk is inherently embedded in time. First they put forward the notion of the risk horizon differentiating short-range risk from long-range risk and examine the risk behaviour of entrepreneurs in terms of their individual future orientation in connection with their risk propensity.

Short-range risk refers to variations in outcomes in the near future, while long-range risk relates to the distant future [65]. However, when people make decisions about the distant future they may be engaged in either low-risk or high-risk long-range risk behaviour. The same individual may well exhibit low-risk behaviour regarding long-range risk and high-risk behaviour regarding shortrange risk or vice versa.

Thus Das and Bing-Sheng Teng develop different entrepreneurial types by employing their distinct risk behaviour in the short run and in the long run. They suggest that craftsman entrepreneurs can be identified by their short-range high risk behaviour, while opportunistic entrepreneurs can be identified by their long-range low-risk behaviour. Their distinction has received empirical support although the findings are far from conclusive [66]. According to Smith [9] a craftsman entrepreneur is characterised by narrowness in education, low social awareness and involvement and they do not offer innovative products. In contrast, an opportunistic entrepreneur is one who typically has breadth in education and training as well as high social awareness and who is involved in providing novel products/services.

It may appear in two cases that an entrepreneurial attitude cannot be developed: when short-range orientation and low-risk behaviour manifest in the same individual as well as when long-range high-risk behaviour also manifest in the same individual.

Does entrepreneurial risk attitude affect entrepreneurial time perception or vice versa? How distinct are the cognitive processes of development of risk attitude and time perception? So far we have seen a situation where the combination of the two attitudes produced particular types of entrepreneurial attitudes. The prevailing of long-lasting attitudes towards the formation of one or other type of entrepreneurship (or some in between forms) may affect the industrial structure permanently or at least for a long period of time. More interesting would be the case where the cognitive process of developing the risk attitude may affect the cognitive process of developing the perception of time. These interrelations may develop not only be- 
cause the cognitive process may be interrelated but because of cultural and social economic factors which determine that the one process may affect the other.

The important point arises when we come to the type of interrelation. If for instance the correlation of the two types of behaviour is positive then there will be a tendency for risk-loving behaviour to be developed in parallel with long-term perception of entrepreneurial commitment which will have serious consequences on the type of entrepreneurial attitude behaviour since, as we have seen, a non-entrepreneurial behaviour is expected to be observed under these circumstances. The interrelation of risk and time attitudes can also affect the entrepreneurial intertemporal rate of substitution. Long-range and riskloving entrepreneurship may be connected with large intertemporal rate substitution while short-range and riskaverting behaviour are connected with a small intertemporal rate of substitution.

Another important point arises as to how the cognitive process of time and risk attitude is developed in relation to entrepreneurial decision-making. In other words the important points are related to the way those attitudes interfere with the entrepreneurial opportunities identification and development. Following the alertness perspective where entrepreneurs may assess opportunities and threats based on a Bayesian probability [36], differing assessments of prospective outcomes may be attributable to differences in prior information as they are filtered by the risk and time attitudes. Therefore time and risk consideration will not enter within entrepreneurial decision-making as any type of investment criteria but as particular types of cognitive attitudes towards the assessment of entrepreneurial decision-making. These attitudes are developed and embodied in entrepreneurial behaviour through a long-lasting procedure originating in the general economic environment as it is mediated by personal traits and cognitive factors.

\section{Structural Change, Time and Risk}

Montobbio [67], in his critical and concentrated literature review, presents three main trends in structural change thinking:

1) endogenous growth models assess the determinants of aggregate growth in a multi-sectoral economy $[15,68]$ which incurs difficulties in explaining major processes of structural changes;

2) the life-cycle models of growth, maturity and decline [69] when they do not have a role for demand pressures and how growth is linked with the declined sectors;

3 ) the supply and demand side factors approach. This last approach seems to have attracted most of the recent work done in the field.

The supply side was first proposed by Schumpeter [70]. Kuznets [71] in the same vein stressed the importance of different impacts of technological innovations and a se- lection mechanism based on the competitive advantage. Pasinetti $[72,73]$ shows that growth rates depend on productivity rates. Baumol [74] and Baumol et al. [75] follow the same reasoning, arguing that stagnant sectors in return of productivity tend to absorb a relatively higher share of employment. Metcalfe [76] also stresses the importance of sectoral differences in productivity without affecting the relative industrial shares in terms of employment. Finally Montobbio [67] shows that positive aggregate productivity growth can be achieved without technological change at the level of firms. This can be achieved, as far as the supply side is concerned, through the effect of sectoral output growth of selection on firm's unit costs.

The demand side approach is also used, usually in connection with the supply side, to explain structural shifts. Kuznets [71] pinpoints the different income elasticity of domestic demand. Pasinetti [72,73] stresses the importance of trends in demand and differentiation of income elasticities. Montobbio [67], as far as the demand side is concerned, emphasises the importance of sorting procedures according to elasticity of substitution of sectoral demand which depends on the institutional characteristics of the market.

From the previous analysis it follows that there are four types of situations which can cause different types of structural change as they arise, all with different possible combinations of time and risk perception:

1) short-term future orientation and risk aversion;

2) long-term future orientation and risk aversion;

3) short-term future orientation and risk loving;

4) long-term future orientation and risk loving.

We may also consider the economy to be characterised by two separate sectors: the equilibrating sector where entrepreneurship produces products and services which match demand and supply and the innovative sector where new creative products are produced. As we have seen, generally speaking we expect that the innovative sector will be characterised by long-term future orientation and risk-averting attitude (the $\mathrm{b}$ situations) while the equilibrating sector will expand to two of the above situations (b and c).

The risk-return relationship holds if the innovative sector equilibrates at a higher level than in the equilibrating sector. The resources move intersectorally according to a) risk-return relationships prevailing in both sectors and $b$ ) the time and risk characteristics of entrepreneurship activated in the sectors. Thus it follows that when time and risk influences reduce the intertemporal rate of substitution while risk and return on innovative sectors are higher than the equilibrating sector, then the innovative portfolio share will be increased. The opposite is true under conditions of enlargement of intertemporal rate of substitution (see Figure 1).

The analysis shows that it can be the case where socie- 
ties develop entrepreneurship which can be classified in one or more of the above two (II, III) quarters depending on a number of factors which have been identified in previous sectors of the paper. Depending on the type of entrepreneurship that is developed (with respect to time and risk characteristics) it is clear that we may have a different type of structural changes growth process which in turn may result in growth rate change.

Is it probable that a growth rate change neutral process may result? It is very unlikely to be the case. There are two reasons for this: a) the two sectors (equilibrating and creative) do not enter under identical (equivalent) conditions of portfolio shares participation and rates of return and risk relationship. Therefore any departure from the initial non 'equivalent' position in the economy will result in a (probably) non-equivalent continuity in the evolution of the portfolio of relative shares; b) the rates of returns of two sectors which reflect the time and risk entrepreneurial consideration are different with the innovative sector characterised by larger levels. This difference in conjunction with the entrepreneur's intertemporal rate of substitution will result in different patterns of portfolio shares expansion.

\section{Conclusions}

The activation of one of the most important components of social capital, which is entrepreneurship, with particular effects through its time and risk characteristics, can be used in order to understand the growth prototypes prevailing in space and time. At the same time we can very well understand that those characteristics are long-lasting accumulated cultural and personal characteristics which cannot be altered through the interference of short-term policies. As a matter of fact the history, political and geostrategical procedures responsible for the establishment of these values should be affected if the structural change process is to be altered. We expect that entrepreneurial risk and time elements will have significant influence on basic growth structural elements such as the portfolio shares of distinct types of entrepreneurial events, the rate of returns on them, and thus the way markets operate.
Finally those basic structural elements will affect the growth rate of the economy itself since there is no reason to suppose that structural changes offset each other.

The risk and time elements interfere with the entrepreneurial identification process and shape the actor's interpretation framework by influencing the stock of knowledge and everyday life. Thus, those factors are not acting as a type of criteria of entrepreneurial decision but are more activated as filters of incoming signalling and information. Most of the institutionalised relationships between individuals, including the derived obligations (and thus expectations as well), are developed in such a way that they are inherent in the particular time and risk horizons and limits prevailing for the entrepreneurial society. By referring to trust issues we may notice that it is very difficult to develop high-trust attitudes under short-term risk-averse behaviour. It is also very probable that under specific conditions the family-based social trust will be prevailing at the expense of community-based trust. It is also clear that entrepreneurs will develop a high perception of risk (irrespective of whether they are characterised nection with social capital and refers to its transparency the transaction costs and thus will affect or reinforce the corresponding rate of social capital. Thus if the institutionalised forms reflect short-term risk-averse attitudes they will tend to enlarge their bureaucratic institutions in order to control this type of attitude. For the same reasons the rationalisation potentiality will cease.

The above analysis pinpoints the fact that it is no longer enough to accept that entrepreneurship enlarges social capital accumulation and vice versa. The important thing lies in what type of social capital is developed under the influence of time and risk entrepreneurial considerations.

Uncertainty affects entrepreneurship. However, what is now evident is that uncertainty affects the way that entrepreneurship is developed, which is the way that the time and risk elements are developed. At the same time, the entrepreneurial time and risk elements affect uncertainty in the economy as entrepreneurs are activated. Long-term risk-seeking activities develop different (larger) levels of uncertainty than long-term risk-averting

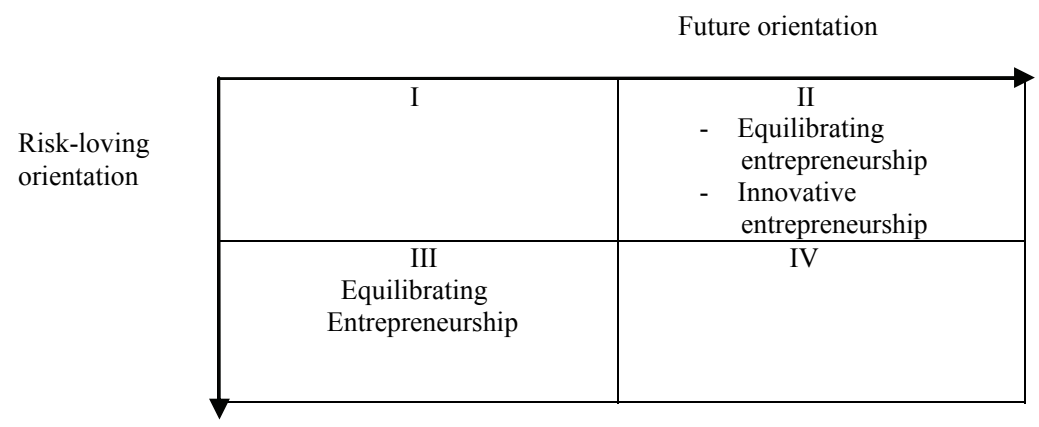

Figure 1. Types of entrepreneurship fostered by time and risk-loving orientation 
entrepreneurship which in fact may not produce any uncertainty. This could be one explanation as to why individuals who could be classified within this cell of combination of attitudes may not be entrepreneurs at all. Under the specific circumstances uncertainty will not act as a starter to the growth process.

According to the risk-return relationship, short-term risk-averting entrepreneurship will lead to a short-term low-return entrepreneurship which could be characterised as the growth structure since it seems that it cannot promise a strong growth prospect, at least in terms of development prototype. The same could be valid in the opposite situation where long-term risk-averting behaviour prevails.

The human capital proxy and more generally social capital could operate as a mediator of short-term, riskaverting educational investment choices which may not affect the growth process positively. Similar scores will be reflected in capital variables.

Generally speaking, if in the economy short-term, riskaverting values on entrepreneurial decisions are prevailing then capital accumulation and capital investment flows will reflect these values. The capital investment will be designed to engage entrepreneurial resources for a short period of time while it will be characterised by a low rate of returns. Obviously, the structural prototype will have these characteristics as well.

The resulting structural prototypes in the different economies are very well connected with the growth rate of change performance. Thus, growth and structural prototypes depend on cultural values and personal traits and especially on time and risk entrepreneurial attitudes. Long-lasting entrepreneurial behaviours are not subject to easily manageable and short-term policy manipulations.

The policy implications of the previous analysis may extend to a variety of fields. One of the immediate results will refer to policies towards upgrading the growth rate of change performance of peripheral economies through structural change which will be based on the introduction of innovative entrepreneurship. It becomes clear that a general policy towards political stability which could reduce risk could be more effective than a huge programme of structural funds development aiming at zero cost capital. This is because the improvement of the entrepreneurial climate, which could be the result of the structural fund development programme (EU structural funds), will lead to a reproduction of the existing industrial process in terms of risk and time characteristics rather than to a required structural change. Thus, it is very probable that the resulting overall rate of change will be weak and correspond to the existing industrial structure. In contrast it becomes evident that the improvement of social capital of the economy through the improvement of entrepreneurial factors by enlarging the investments of human capital (education and continuous education) will change atti- tudes towards innovation and result in an acceptable longer time of entrepreneurial commitment.

\section{REFERENCES}

[1] P. M. Romer, "Increasing returns and long-run graph," Journal of Political Economy, Vol. 94, No. 5, pp. 1002-1037, 1986.

[2] R. J. Lucas, "On the mechanics of economic development," Journal of Monetary Economics, No. 22, pp. 3-42, January 1988.

[3] C. V. Vaitsos and A. Bartzokas, "Developmental economics," Kritiki Publications, Athens, 2004.

[4] C. V. Vaitsos, "Growth theories revisited: Enduring questions with changing answers," Discussion Paper, University of Athens, Athens, 2003.

[5] B. Piazza-Georgi, "The role of human and social capital in growth: Extending our understanding," Cambridge Journal of Economics, No. 26, pp. 461-479, 2002.

[6] S. Shane and S. Venkataraman, "The promise of entrepreneurship as a field of research," Academy of Management Review, Vol. 25, No. 1, pp. 217-226, 2000.

[7] H. Barreto, "The entrepreneur in microeconomic Theory," Routledge Press, London, 1989

[8] R. Khilstrom and J. Laffont, "A general equilibrium entrepreneurial theory of firm formation based on risk aversion," Journal of Political Economy, No. 87, pp. 719-748, 1979.

[9] A. Smith, "An inquiry into the nature and causes of the wealth of nations," New York: Modern Library, 1937.

[10] I. M. Kirzner, "Competition and entrepreneurship," University of Chicago Press, Chicago, 1973.

[11] J. Schumpeter, "The theory of economic development," Harvard University Press, Cambridge (Mass), 1934.

[12] F. Hayek, "The use of knowledge in society," American Economic Review, No. 35, pp. 519-530, 1945.

[13] D. Ricardo, “The Principles of Political Economy,' 3rd ed., Joseph Malaby Dent, London, 1912.

[14] R. M. Solow, "A contribution to the theory of economic growth," Quarterly Journal of Economics, Vol. 70, pp. 65-94, February 1956.

[15] P. M. Romer, "Endogenous technical change," Journal of Political Economy, No. 98, pp. 71-102, 1990.

[16] R. G. Holcombe, "Entrepreneurship and economic growth," Quarterly Journal of Austrian Economics, Vol. 1, No. 2, pp. 45-62, Summer 1998.

[17] T. F. L. Yu, "Entrepreneurial alertness and discovery," Review of Austrian Economics, Vol. 14, No. 1, pp. 47-63, 2001.

[18] A. Portes and P. Landolt, "The downside of social capital," The American Prospect, No. 26, pp. 18-21, 1996.

[19] H. Westlund and R. Bolton, "Local social capital and entrepreneurship," Small Business Economics, No. 21, pp. 77-113, 2003.

[20] P. Bourdienn and L. J. D. Wacquant, “An Invitation to 
Reflexive Sociology," University of Chicago Press, Chicago, Illinois, 1992.

[21] J. S. Coleman, "Social capital in the creation of human capital," American Journal of Sociology (Supplement), No. 94, pp. 95-120, 1988.

[22] J. S. Coleman, "Foundations of social theory," Cambridge, MA: Harvard University Press, 1990.

[23] F. Fukuyama, "Trust: The social virtues and the creation of prosperity," Hamish Hamilton, London, 1995.

[24] M. Woolcock, "Social capital and economic development: Towards a theoretical synthesis and policy framework," Theory and Society, Vol. 27, No. 2, pp. 151-208, 1998.

[25] J. W. Fedderke, R. H. J. De Kadt, and J. Luiz, "Growth and social capital: A critical reflection," Theory and Society, No. 28, pp. 709-745, 1999.

[26] T. F. L. Yu, "An entrepreneurial perspective of institutional change," Constitutional-Political-Economy, Vol. 12, No. 3, pp. 217-236, 2001.

[27] G. Dosi and F. Malebra, "Organizational learning and institutional embeddedness," In: Organization and Strategy in the Evolution of the Enterprise, Macmillan, London, pp. 1-24, 1996.

[28] M. Brouwer, "Entrepreneurship and uncertainty: Innovation and competition among many," Small Business Economics, No. 15, pp. 149-160, 2000.

[29] H. Markowitz, "Portfolio selection," Journal of Finance, No. 7, pp. 77-91, 1952.

[30] J. Tobin, "Liquidity preference as a behaviour towards risk," Review of Economic Studies, No. 25, pp. 65-66, 1958.

[31] W. F. Sharpe, "Capital asset prices: A theory of market equilibrium under conditions of risk," Journal of Finance, No. 33, pp. 885-901, 1964.

[32] P. E. Petrakis, "Entrepreneurship and risk premium," Journal of Small Business Economics, Vol. 23, No. 2, pp. 85-98, 2004.

[33] D. Acemoglu and F. Zilibotti, "Was Prometheus unbound by chance? Risk, diversification, and growth," Journal of Political Economy, Vol. 105, No. 4, pp. 709-751, 1997.

[34] D. Forlani and J. W. Mullins, "Perceived risks and choices in entrepreneurs' new venture decisions," Journal of Business Venturing, No. 15, pp. 305-322, 2000.

[35] F. Yates and E. R. Stone, "The risk construct," In: F. Yates Ed., Risk-Taking Behavior, John Wiley \& Sons, pp. 1-26, 1992.

[36] W. I. Norton and W. T. Moore, "Entrepreneurial risk: Have we been asking the wrong question?" Small Business Economics, Vol. 18, No. 4, pp. 281-287, 2002.

[37] D. M. Ray, "The role of risk-taking in Singapore," Journal of Business Venturing, Vol. 9, No. 2, pp. 157-177, 1994.

[38] F. H. Knight, "Risk, uncertainty and profit," Houghton Mifflin, New York, 1921.

[39] I. S. Baird and H. Thomas, "Toward a contingency model of strategic risk taking," Academy of Management Review, Vol. 10, No. 2, pp. 230-243, 1985.
[40] S. B. Sitkin and L. R. Weingart, "Determinants of risky of decision-making behavior: A test of the mediating role of risk perception and propensity," Academy of Management Journal, Vol. 38, No. 6, pp. 1573-1592, 1995.

[41] S. B. Sitkin and A. Pablo, "Reconceptualizing the determinants of risk behaviour," Academic Management Review, No. 17, pp. 9-38, 1992.

[42] T. K. Hean, D. F. Maw, and C. L. Boon, "Opportunity evaluation under risky conditions: The cognitive processes of entrepreneurs," Entrepreneurship Theory and Practice, Vol. 27, No. 2, pp. 125-148, 2002.

[43] M. Simon, S. M. Houghton, and K. Aquino, "Cognitive biases, risk perception, and venture formation: How individuals decide to start companies," Journal of Business Venturing, Vol. 15, No. 2, pp. 113-134, 2000.

[44] L. W. Busenitz and J. B. Barney, "Differences between entrepreneurs and managers in large organizations: Biases and heuristics in strategic decision-making," Journal of Business Venturing, Vol. 12, No. 1, pp. 9-30, 1997.

[45] A. C. Cooper, C. Y. Woo, and W. C. Dunkelberg, "Entrepreneurs' perceived chances foe success," Journal of Business Venturing, Vol. 3, No. 1, pp. 97-108, 1988.

[46] L. E. Palich and D. R. Bagby, "Using cognitive theory to explain entrepreneurial risk-taking: Challenging conventional wisdom," Journal of Business Venturing, Vol. 10, No. 6, pp. 425-438, 1995.

[47] R. H. Brockhaus, "Risk taking Propensity of entrepreneurs," Academy of Management Journal, Vol. 23, No. 3, pp. 509-520, 1980.

[48] R. Masters and R. Meir, "Sex differences and risk-taking propensity of entrepreneurs," Journal of Small Business Management, Vol. 26, No. 1, pp. 31-35, 1988.

[49] D. Ghosh and M. R. Ray, "Risk, ambiguity, and decision choice: Some additional evidence," Decision Sciences, Vol. 28, No. 1, pp. 81-104, 1997.

[50] A. Ardichvili, R. Cardozo, and S. Ray, "A theory of entrepreneurial opportunity identification and development," Journal of Business Venturing, Vol. 18, No. 1, pp. 105-123, 2003.

[51] I. M. Kirzner, "Perception, opportunity and profit," University of Chicago Press, Chicago, 1979.

[52] J. A. Timmons, D. F. Muzyka, H. H. Stevenson, and W. D. Bygrave, "Opportunity recognition: The core of entrepreneurship," In: R. H. N. C. Brockhaus, W. C. Churchill, J. Katz, B. A. Kirchhoff, K. H. Vesper, and W. Wetzel (Wellesley ed.), Frontiers of Entrepreneurship Research, MA: Babson College, pp. 109-123, 1987.

[53] R. Ronstandt, "The corridor principle," Journal of Business Venturing, Vol. 1, No. 3, pp. 31-40, 1988.

[54] R. D. Teach, R. G. Schawartz, and F.A. Tarpley, "The recognition and exploitation of opportunity in the software industry: A study of surviving firms," In: R. H. Brockhaus, W. C. Churchill, J. Katz, B. A. Kirchhoff, K. H. Vesper, and W. Wetzel (Wellesley ed.), Frontiers of Entrepreneurship Research, MA: Babson College, pp. 383-397, 1989.

[55] A. de Koning, "Conceptualizing opportunity recognition 
as a socio-cognitive process," Centre for Advanced Studies in Leadership, Stockholm, 1999.

[56] C. Lechner and M. Dowling, "Firm networks: External relationships as sources for the growth and competitiveness of entrepreneurial firms," Entrepreneurship and Regional Development, Vol. 15, No. 1, pp. 1-26, 2003.

[57] A. Anderson and S. Jack, "The articulation of social capital in entrepreneurial networks: A glue of a lubricant?" Vol. 14, No. 3, pp. 193-210, 2002.

[58] L. Hurmerinta-Peltomäki, "Time and internationalisation, theoretical challenges set by rapid internationalisation," Journal of International Entrepreneurship, Vol. 1, No. 2, pp. 217-236, 2003.

[59] T. Chapman, "Time: A Philosophical Analysis," Dordrecht, D. Reidel, Holland, 1982.

[60] B. J. Bird and G. P. West III, "Time and entrepreneurship," Entrepreneurship Theory and Practice, Vol. 22, No. 2, pp. 5-136, 1997.

[61] T. K. Das and B. S. Teng, "Time and entrepreneurial risk behaviour," Entrepreneurship Theory and Practice, Vol. 22, No. 2, pp. 69-88, 1997.

[62] S. L. Derby and R. L. Keeney, "Risk analysis: Understanding 'How Safe is Safe Enough?"' Risk Analysis, Vol. 1, No. 3, pp. 217-224, 1981.

[63] L. H. Strickland, R. J. Lewicki, and A. Katz, "Temporal orientation and perceived control as determinants of risk taking," Journal of Experimental Social Psychology, No. 2, pp. 134-151, 1966.

[64] C. Vlek and P. J. Stallen, "Rational and personal aspects of risk," Acta Psychologica, No. 45, pp. 273-300, 1980.

[65] P. F. Drucker, "What we can learn from Japanese management," Harvard Business review, Vol. 49, No. 2, pp. $110-122,1971$.
[66] C. Y. Woo, A. C. Cooper, and W.C. Dunkelberg, "The development and interpretation of entrepreneurial typologies," Journal of Business Venturing, Vol. 6, No. 2, pp. 93-111, 1991.

[67] F. Montobbio, "An evolutionary model of industrial growth and structural change," Structural Change and Economic Dynamics, No. 13, pp. 387-414, 2002.

[68] P. Aghion and P. Howitt, "Endogenous growth theory," MIT Press, Cambridge, 1998.

[69] D. Audretch, "An empirical test of the industry life cycle," Welwirtschaftliches Archiv, Vol. 123, No. 2, pp. 297-307, 1987.

[70] J. Schumpeter, "The instability of capitalism," The Economic Journal, No. 38, pp. 361-386, 1928.

[71] S. Kuznets, "Economic development, the family and income distribution," Selected Essays, Cambridge University Press, Cambridge, 1988.

[72] L. Passinetti, "Structural change and economic growth: A theoretical essay on the dynamics of the wealth of nations," Cambridge University Press, Cambridge, 1981.

[73] L. Passinetti, "Structural change and economic dynamics," Cambridge University Press, Cambridge, 1993.

[74] W. J. Baumol, "Macroeconomics of unbalanced growth: The anatomy of urban crisis," American Economic Review, No. 57, pp. 415-426, 1967.

[75] W. J. Baumol, S. A. B. Batey, and E. N. Wolff, "Unbalanced growth revisited: Asymptotic stagnancy and new evidence," American Economic Review, No. 75, pp. 806-817, 1985.

[76] J. S. Metcalfe, "Restless capitalism: Increasing returns and growth in enterprise economics," Manchester (CRIC): Mimeo, March 1999. 